Hypothesis

\title{
Drugs, Metabolites, and Lung Accumulating Small Lysosomotropic Molecules: Multiple Targeting Impedes SARS-CoV-2 Infection and Progress to COVID-19
}

\author{
Markus Blaess $^{1}\left(\mathbb{D}\right.$, Lars Kaiser ${ }^{1,2}(\mathbb{D})$, Oliver Sommerfeld ${ }^{3}\left(\mathbb{D}\right.$, René Csuk ${ }^{4}(\mathbb{D})$ and Hans-Peter Deigner ${ }^{1,5,6} * *^{(D)}$ \\ 1 Institute of Precision Medicine, Medical and Life Sciences Faculty, Furtwangen University, \\ Jakob-Kienzle-Str. 17, D-78054 Villingen-Schwenningen, Germany; markus.blaess@web.de (M.B.); \\ La.Kaiser@hs-furtwangen.de (L.K.) \\ 2 Institute of Pharmaceutical Sciences, University of Freiburg, Albertstraße 25, D-79104 Freiburg, Germany \\ 3 Department of Anaesthesiology and Intensive Care Medicine, Jena University Hospital, Am Klinikum 1, \\ D-07747 Jena, Germany; Oliver.Sommerfeld@med.uni-jena.de \\ 4 Organic Chemistry, Martin-Luther-University Halle-Wittenberg, Kurt-Mothes-Str. 2, \\ D-06120 Halle (Saale), Germany; rene.csuk@chemie.uni-halle.de \\ 5 Fraunhofer Institute IZI, Leipzig, EXIM Department, Schillingallee 68, D-18057 Rostock, Germany \\ 6 Faculty of Science, Tuebingen University, Auf der Morgenstelle 8, D-72076 Tübingen, Germany \\ * Correspondence: Hans-Peter.Deigner@hs-furtwangen.de; Tel.: +49-7720-307-4232
}

Citation: Blaess, M.; Kaiser, L. Sommerfeld, O.; Csuk, R.; Deigner, H.-P. Drugs, Metabolites, and Lung Accumulating Small Lysosomotropic Molecules: Multiple Targeting Impedes SARS-CoV-2 Infection and Progress to COVID-19. Int. J. Mol. Sci. 2021, 22, 1797. https://doi.org/ 10.3390/ijms22041797

Academic Editor: Manuel Scimeca

Received: 5 January 2021

Accepted: 3 February 2021

Published: 11 February 2021

Publisher's Note: MDPI stays neutral with regard to jurisdictional claims in published maps and institutional affiliations.

Copyright: (c) 2021 by the authors. Licensee MDPI, Basel, Switzerland. This article is an open access article distributed under the terms and conditions of the Creative Commons Attribution (CC BY) license (https:// creativecommons.org/licenses/by/ $4.0 /)$

\begin{abstract}
Lysosomotropism is a biological characteristic of small molecules, independently present of their intrinsic pharmacological effects. Lysosomotropic compounds, in general, affect various targets, such as lipid second messengers originating from lysosomal enzymes promoting endothelial stress response in systemic inflammation; inflammatory messengers, such as IL-6; and cathepsin L-dependent viral entry into host cells. This heterogeneous group of drugs and active metabolites comprise various promising candidates with more favorable drug profiles than initially considered (hydroxy) chloroquine in prophylaxis and treatment of severe acute respiratory syndrome coronavirus 2 (SARS-CoV-2) infections/Coronavirus disease 2019 (COVID-19) and cytokine release syndrome (CRS) triggered by bacterial or viral infections. In this hypothesis, we discuss the possible relationships among lysosomotropism, enrichment in lysosomes of pulmonary tissue, SARS-CoV-2 infection, and transition to COVID-19. Moreover, we deduce further suitable approved drugs and active metabolites based with a more favorable drug profile on rational eligibility criteria, including readily available over-the-counter (OTC) drugs. Benefits to patients already receiving lysosomotropic drugs for other pre-existing conditions underline their vital clinical relevance in the current SARSCoV2/COVID-19 pandemic.
\end{abstract}

Keywords: SARS-CoV-2; COVID-19; lysosomotropism; metabolites; cytokine storm; viral host cell entry; approved drugs; pulmonary tissue accumulation; drug repurposing; eligibility criteria

\section{Introduction}

Severe acute respiratory syndrome coronavirus 2 (SARS-CoV-2) has been identified as the disease-causing pathogen of the pandemic Coronavirus disease 2019 (COVID-19) outbreak, posing serious challenges to health care systems worldwide. The most recent COVID-19 treatment guidelines published by the National Institutes of Health (NIH) [1] state that at present there is still no drug proven to be safe and effective for pre-exposure prophylaxis of SARS-CoV-2 infection. To date, dexamethasone and the recently approved nucleotide prodrug remdesivir are recommended for hospitalized COVID-19 patients requiring supplemental oxygen or noninvasive ventilation, and dexamethasone in case of extracorporeal membrane oxygenation (ECMO) or invasive mechanical ventilation. Moreover, the NIH meanwhile discourages the previously hotly-favored use of anti-IL6 receptor antibodies (e.g., sarilumab, tocilizumab) or anti-IL-6 antibody (siltuximab), 
and ivermectin, except in a clinical trial [1]. There is still a need for action in the field of individual prophylaxis of SARS-CoV-2 infection and therapy of COVID-19 because of the rapidly increasing number of cases.

Lately, lysosomes have gained increasing attention in drug repurposing since they are considered to function as the key cell organelle involved in the SARS-CoV-2 infection of nasal and pulmonary tissue [2-6]. Repurposing of approved active compounds, with particular regard to their metabolites accumulating in the lysosomes of pulmonary tissue and mononuclear cells, could be a strategy to bridge this gap and to achieve a better outcome, unlike (hydroxy) chloroquine administration in COVID-19 [1] and SARS [7]. On the other hand, the use of these active compounds in the treatment of preexisting diseases, such as bacterial or fungal infections, mental illness, allergies, and hypertension, could be one reason for the variation in severities of the pandemic in distinct industrial countries.

\section{2. (Endo) Lysosomes, Viral Replication, and Infection of Airway Epithelial Cells Are Therapeutic Targets of Small Lysosomotropic Molecules}

Both SARS-CoV and SARS-CoV-2 engage their receptor, angiotensin-converting enzyme 2 (ACE2), on the cell surface for host cell entry. If human airway trypsin-like protease [8] is not expressed on host cell surface, both enter the cytoplasm through endosomes and travel along the endocytic pathway. Finally, in lysosomes active cathepsin L (BRENDA:EC 3.4.22.15; optimum pH 5.0-5.5) induces the fusion of SARS particles bound to ACE2 with host cells by cleavage of the viral S-protein [9]. Cathepsin L-induced fusion of SARS-CoV particles with host cells can be impeded via preventing (endo)lysosomal acidification by vacuolar $\mathrm{H}^{+}$-ATPase (V-ATPase; BRENDA:EC 3.6.3.6) using bafilomycin or via lysosomotropism and unspecific cathepsin L inhibition using lysosomotropic teicoplanin [10]. Moderate lysosomotropic compounds, such as chloroquine, hydroxychloroquine, fluspirilene, and clomipramine, have been found to abolish SARS-CoV-2 infection in Vero E6 cells [11-13]; chloroquine exerts antiviral SARS-CoV effects in vitro during pre- and post-infection conditions, impairs the terminal glycosylation of ACE2 at anti-SARS-CoV concentrations, and inhibits viral entry.

Interestingly, SARS-CoV-2 is capable of directly infecting cells by an infected neighboring cell without the release of a complete virus from infected cells via exocytosis. S-protein-related formation of multinucleate cells (syncytia) depends on presentation of ACE2 on the surface of the neighboring host cell. Syncytia has been observed in SARS-CoVinfected cell cultures, primates, and SARS patients [14] and is probably linked to lysosomal ceramide metabolism and lysosomal $\mathrm{C}_{16^{-}} / \mathrm{C}_{18^{-}}$-ceramide synthesis. These findings suggest that both prophylactic and therapeutic effects lysosomotropic compounds in general are likely and are summarized in Table 1.

Transmembrane serine protease 2 (TMPRSS2), a member of the transmembrane protease/serine subfamily (TMPRSS), has been reported to induce SARS-CoV-2 fusion (Sprotein priming) with membranes of airwave epithelial cells [8]. Cell culture experiments revealed, however, that TMPRSS2 inhibitors are only efficient in SARS-CoV-2 infection if the viral host cell entry is exclusively mediated by TMPRSS2. Once the cathepsin L-dependent endocytic, ACE2 receptor-mediated pathway of infection participates, the effectiveness of TMPRSS2 inhibitors (e.g., nafamostat) decreases rapidly [15] and becomes unpromising for drug repurposing. 
Table 1. Potential scope of approved lysosomotropic drugs, RNA-dependent RNA polymerase (RdRp) severe acute respiratory syndrome coronavirus 2 (SARS-CoV-2) antivirals (remdesivir), and transmembrane serine protease 2 (TMPRSS2) inhibitors (nafamostat, camostat), in the prophylaxis and severity of SARS-CoV-2 infection/COVID-19. Depending on the impact on downstream signaling pathways/effects and on the disease process, the drug interventions are classified as indicated: $++/+$ with putative (very) strong impact; o with putative low / moderate impact; - with putative no impact; * inhibits serine proteases related to coagulation and fibrinolysis and prevents (sepsis-related) disseminated intravascular coagulation and thrombotic microangiopathy; sufficient TMPRSS2 inhibiting concentration questionable in lung tissue within the therapeutic margin; \# proven in animals (SARS-CoV-2) [16] or observation in psychiatry hospitals [17].

\begin{tabular}{cccc}
\hline $\begin{array}{c}\text { Prophylaxis/Severity } \\
\text { of Disease }\end{array}$ & $\begin{array}{c}\text { Impact of } \\
\text { Lysosomotropic } \\
\text { Compounds }\end{array}$ & $\begin{array}{c}\text { SARS-CoV-2 } \\
\text { RdRp Antivirals } \\
\text { (Remdesivir) }\end{array}$ & $\begin{array}{c}\text { TMPRSS2 } \\
\text { Inhibitors }\end{array}$ \\
\hline $\begin{array}{c}\text { Pre-Exposure Prophylaxis } \\
\text { Asymptomatic or }\end{array}$ & $+/ \#$ & $+/ \#$ & $+/^{\circ}$ \\
Pre-Symptomatic Infection & 0 & 0 & 0 \\
Mild Illness & + & + & $-/^{*}$ \\
Severe Illness & ++ & ++ & $-/^{*}$ \\
Critical Illness & ++ & ++ & $-/^{*}$ \\
\hline The coloring underlines the severity of the disease / condition of the patient.
\end{tabular}

\section{Tackling the CRS/Cytokine Storm Syndrome in COVID-19}

SARS-CoV-2 is likely to cause pulmonary and systemic inflammation, thus leading to multi-organ dysfunction (e.g., acute respiratory distress syndrome (ARDS), myocarditis, and sepsis). The increase of systemic production and the substantial release of IL-8, TNF $\alpha$, and IL-6 $[18,19]$ have been considered central mediators of toxicity in cytokine release syndrome (CRS)/cytokine storm syndrome [20] and contribute to the pathophysiology of severe COVID-19 [21]. ARDS/severe COVID-19 pneumonia is often accompanied by the macrophage activation syndrome (MAS) or an IL-6-mediated very low human leukocyte antigen D related (HLA-DR) expression; a profound depletion (lymphopenia) of CD4 lymphocytes, CD19 lymphocytes, and natural killer (NK) cells; and hyper-inflammation [19].

In monocytic cells, the lysosmotropic model compound NB 06 diminishes LPS-induced surge of the prominent inflammatory messengers IL-1B; IL-23A; CCL4; CCL20; and, in particular, IL-6 [22]; likewise, beneficial effects in (systemic) infections involving bacterial endotoxins, such as LPS, by targeting the TLR4 receptor pathway in sepsis are obvious. Moreover, lysosomotropic desipramine reduces endothelial stress response in systemic inflammation owing to peritoneal infection [23]. Comparable high expression of IL-1B, IL-6, CCL4, CXCL10, and highly elevated serum levels of IL-6 have been observed in murine lung lobes infected with influenza A (H1N1) virus [24].

\section{Lysosomotropic Drugs vs. IL-1 and IL-6 Inhibitors or Anti-IL-6R in COVID-19 Treatment}

Various clinical trials on the use of immunomodulatory IL-1 and IL-6 inhibitors or anti-IL-6R antibodies (anakinra, tocilizumab, and sarilumab) in patients with COVID-19 are currently under way (https://clinicaltrials.gov/ct2/home). In limited yet available clinical data, tocilizumab, as well as sarilumab, have failed to demonstrate efficacy and benefit in survival. The NIH, therefore, discourages the use of IL-6 or IL-6 receptor antibodies, except in a clinical trial [1], considering the risk of serious adverse effects due to massive interventions in the immune system (e.g., bacterial upper respiratory tract infection, pneumonia, and viral infections). As a way out of this dilemma, it would be preferable to prevent the excessive emergence of this messenger by clever selection of lysosomotropic drugs rather than to trap them after excessive release. Some benefits and targets that are not addressed with antibodies but are with lysosomotropic drugs are enumerated below (Figure 1). 


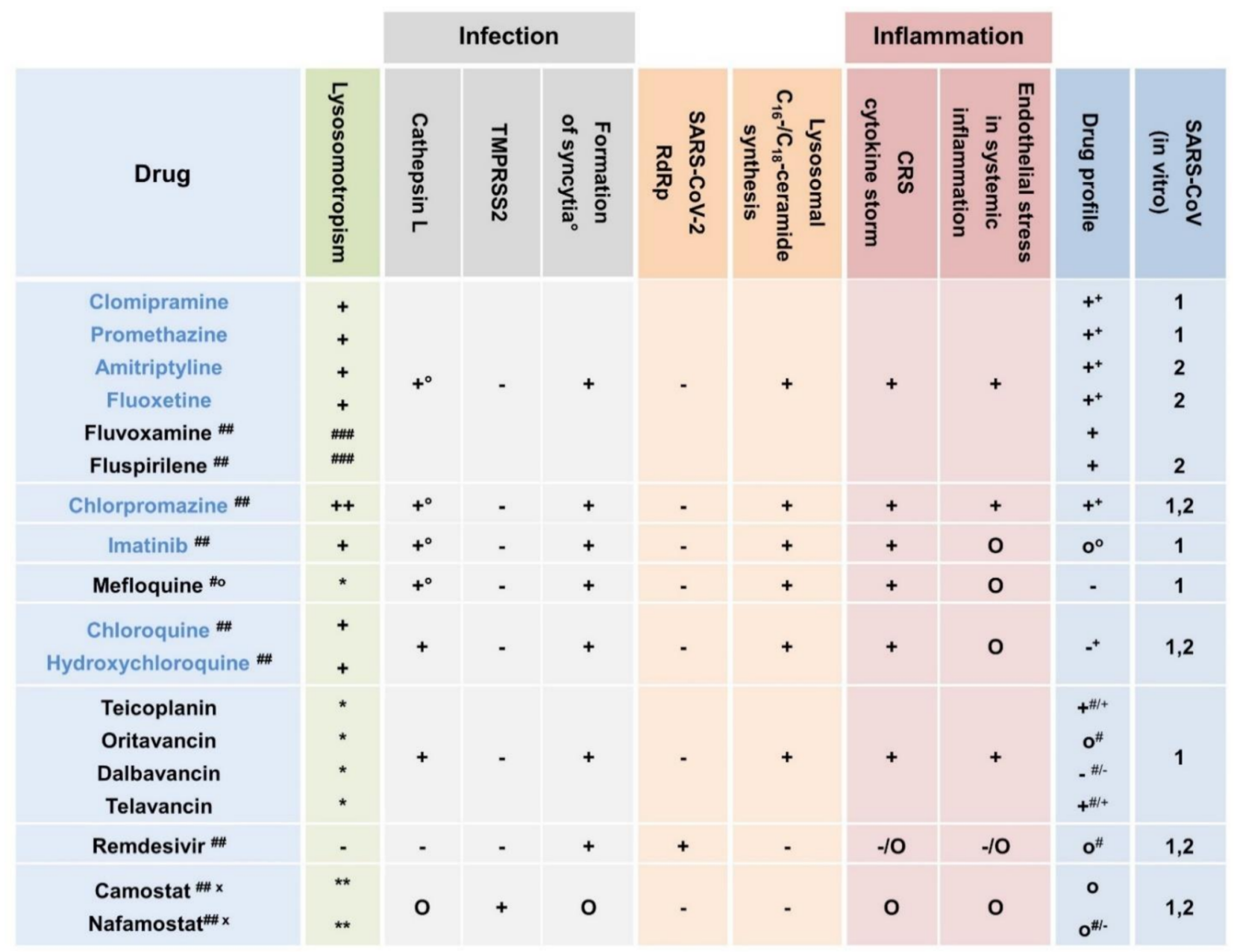

Figure 1. Variety of approved compounds for targets in SARS-CoV-2 infection/Coronavirus disease 2019 (COVID-19). Lysosomotropism: achievement of the desired lysosomotropic effect depended on the drug, the dosage, and accumulation in pulmonary tissue and in lysosomes. Unless indicated, maximum daily doses are typically split into three applications according to the patient information leaflet/market authorization. Confirmed lysosomotropism (blue colored): lysosomal drug concentration (effect) within the therapeutic margin in vivo (expected): (++) occurs at maximum daily dosage and very likely in low or initial dosage, $(+)$ very likely at maximum daily dosage and possible in low or initial dosage. Supposed lysosomotropism: $\left(^{*}\right)$ lysosomotropism very likely but not yet confirmed, lysosomal drug concentration (effect) within the therapeutic margin expected; $\left.{ }^{* *}\right)$ lysosomotropism likely but not yet confirmed, lysosomal drug concentration (effect) within the therapeutic margin not expected; $\left({ }^{\# \#}\right)$ lysosomotropism very likely but not yet confirmed, no lysosomal drug concentration (effect) within the therapeutic margin expected. Efficacy on targets cathepsin L, TMPRSS2, formation of syncytia, SARS-CoV-2 RdRp, lysosomal $\mathrm{C}_{16^{-}} / \mathrm{C}_{18^{-}}$-ceramide synthesis, endothelial stress in systemic inflammation, and CRS/cytokine storm [8,10-12,22,25-29]: $\left(+^{\circ}\right)$ proven in vitro; $(+)$ is very likely; $(\mathrm{O})$ is (mediated) possible; $(-)$ no effect. Drug profile: (+) good; (o) moderate; (-) worse, assessment depending on elimination half-life and severe adverse effects; accumulation in pulmonary tissue: $\left(^{+}\right)$proven, $\left(^{\circ}\right)$ likely, $\left(^{-}\right)$no accumulation in pulmonary tissue; $\left(^{\#}\right)$ only intravenous application; $\left(^{(\#)}\right.$ ) in COVID-19 clinical trials; $\left({ }^{\# 0}\right)$ dosage depending on treatment or prophylaxis (of malaria); ${ }^{*}$ inhibits serine proteases related to coagulation and fibrinolysis, and prevents (sepsis-related) disseminated intravascular coagulation and thrombotic microangiopathy; $\left({ }^{\mathrm{x}}\right)$ sufficient TMPRSS2 inhibiting concentration questionable in pulmonary tissue within the therapeutic margin.

First of all, lysosomotropic compounds are supposed to tackle the CRS/cytokine storm syndrome in transition to COVID-19. Second, they prevent the required lysosomal acidification for fusion-activating cathepsin $\mathrm{L}$ activity to diminish or prevent airwave cell infection by releasing viral RNA. Third, lysosomotropic compounds have an impact on lysosomal ceramide metabolism. Of particular interest is an assumed exocytosis-triggering effect of $\mathrm{C}_{18}$-ceramide [30], leading to cell-cell fusion of fractions of viral S-protein and 
formation of syncytia. Lysosomotropic drugs prevent apoptosis and lysosomal synthesis of $\mathrm{C}_{16}$-ceramide [22], and are supposed to prevent exocytosis-triggering $\mathrm{C}_{18}$-ceramide. Fourth, lysosmotropic drugs provide protection against endothelial stress response in systemic inflammation and sepsis-induced cardiac dysfunction [23]. Fifth, active compounds of various indications share lysosomotropic characteristics and partly display more suitable drug profiles than (hydroxy) chloroquine. Furthermore, their N-desmethyl metabolites share most likely lysosomotropism as well.

\section{Lysosomotropism, Lysosomes, Lysosomal pH, NADPH, V-ATPase, and the Release of Virions}

To date, an unanswered question is how the exocytosis of virions mechanistically occurs from infected cells. Non-lytic release of beta-coronaviruses, such as SARS-CoV-2, results in lysosome deacidification, inactivation of lysosomal degradation enzymes, and disruption of antigen presentation [31]. Conversely, it can be hypothesized that the lysosomal deacidification is necessary for the exocytosis of virions. Accordingly, $\mathrm{C}_{18}$-ceramide (and $\mathrm{C}_{16}$-ceramide) can be formed in lysosomes, triggering the formation of vesicles and exocytosis of virions.

The key point is the interaction of lysosomal acidic ceramidase (aCERase), the lysosomal vacuolar $\mathrm{H}^{+}$-ATPase (V-ATPase), and NADPH. Interestingly, lysosomal acidic ceramidase (aCERase) exhibits two different intergradient enzymatic activities depending on the lysosomal pH: a ceramide hydrolase activity (optimum $\mathrm{pH} 4.0-5.0$ ) and a little-known ATP-independent reverse ceramide synthase activity (revaCERase) (optimum pH 5.5-6.5). RevaCERase preferentially reacts palmitic acid $\left(\mathrm{C}_{16}\right)$ and stearic acid $\left(\mathrm{C}_{18}\right)$ with sphingosine [32,33]. In the event of oxidative stress, stearic acid and palmitic acid are derived from palmitoyl-CoA or stearoyl-CoA by palmitoyl-CoA hydrolase from fatty acid synthesis, if ELOVL-catalyzed elongation to very long chain fatty acids is impeded due to NADPH deficiency. NADPH serves as an activator of ELOVL 6 and 7 [34].

Deficiency of cytosolic NADH and ATP, e.g., in oxidative stress, collapses the lysosomal proton gradient powered by the lysosomal redox chain and the V-ATPase [35,36]. Under such conditions, the short-chain ceramides $\mathrm{C}_{16}$-ceramide and $\mathrm{C}_{18}$-ceramide can be formed.

However, in absence of cellular oxidative stress, neither $C_{16}$-ceramide nor $C_{18}$-ceramide are formed in lysosomes [37]; elongation of palmitoyl-CoA and stearoyl-CoA to very long chain fatty acids is not impeded. In presence of lysosomotropic compounds, the ongoing synthesis of long-chain ceramides leads to an accumulation of long-chain ceramides (e.g., $\mathrm{C}_{24: 1}$-ceramide) [22] without triggering vesicle formation [30].

\section{Chlorpromazine: Pulmonary Tissue Accumulation and Protection from SARS-CoV-2 Infection/COVID-19}

Predicted protective effects of particular lysosmotropic drugs in SARS-CoV-2 infection/ COVID-19 are supported by observations in patients treated with chlorpromazine. Patients displayed a significantly lower prevalence of symptomatic and severe forms of COVID-19 ( $4 \%)$ compared to staff $(14 \%)$ operating in the same facilities [17]. Single dose distribution experiments demonstrated a lasting enrichment of chlorpromazine in pulmonary tissue (tissue/plasma ratio of 30) $60 \mathrm{~min}$ after intravenous application [38]. In line with in vitro data of chlorpromazine [12,27], various lysosomotropic drugs (Figure 2a,b) are likely to provide anti SARS-CoV(-2) effects in patients if pulmonary enrichment leads to an effective antiviral (lysosomotropic drug) concentration in vivo.

Despite the aforementioned protection, chlorpromazine is inappropriate for systemic prophylaxis of infection in healthy individuals. The intrinsic pharmacological effects of chlorpromazine now turn into undesirable adverse effects (e.g., dry mouth, bloating or stomach cramps, and feeling restless [39]) in people without mental illness. A reasonable solution of this quandary is the inhalation of chlorpromazine-containing-solutions for SARS-CoV-2 infection prophylaxis, as this enables us to accurately target the area of viral host cell entry. 

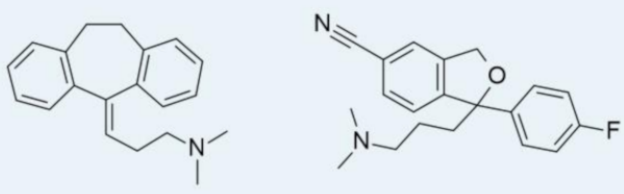

amitriptyline * $(r=22)$
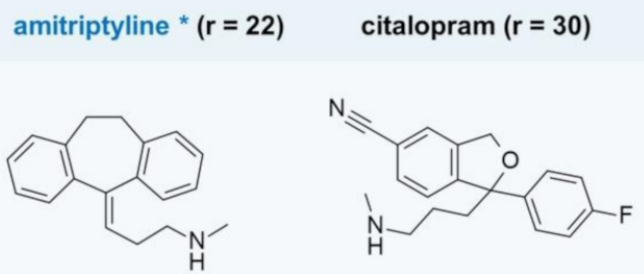

desmethyl

nortriptyline * $(r=16)$

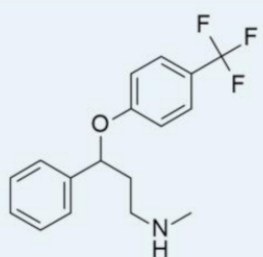

fluoxetine * $(r=50)$

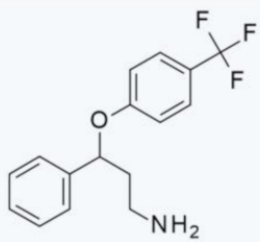

norfluoxetine * $(r=60)$ citalopram ${ }^{\#}(r=40)$

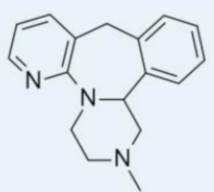

mirtazapine $(r=3)$

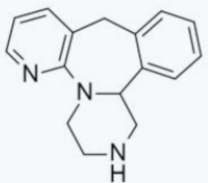

normirtazapine $(r=17)$

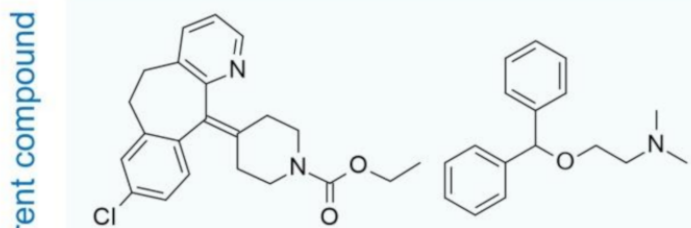

diphenhydramine *<smiles>CNCCOC(c1ccccc1)c1ccccc1</smiles>

$\mathrm{N}$-desmethyl diphenhydramine<smiles>CCOc1ccc(Cl)cc1C1=C2CCNCC2CCc2cccnc21</smiles><smiles>CCN(CC)CCNC(=O)c1cc(Cl)c(N)cc1OC</smiles>

metoclopramide

levofloxazcin<smiles>C[C@H]1COc2c(N3CCNCC3)c(F)cc3c(=O)c(C(=O)O)cn1c23</smiles>

N-desethyl metoclopramide<smiles>CN(Cc1cc(Br)cc(Br)c1N)C1CCCCC1</smiles>

bromhexine<smiles>Nc1c(Br)cc(Br)cc1CNC1CCC(O)CC1</smiles>

ambroxol

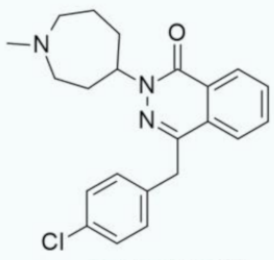

azelastine **

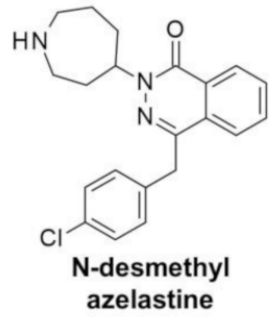

(a)

(b)

Figure 2. Lysosomotropic candidates and pulmonary tissue accumulation: (a) pairs of confirmed (blue colored) and potential lysosomotropic drugs and their $\mathrm{N}$-desmethyl metabolites with proved enrichment in pulmonary tissue (ratio of pulmonary tissue/plasma concentration $r>1$ ) [40-42]. $\left({ }^{\#}\right)$ Ratio determined in rats, $\left({ }^{*}\right)$ lysosomotropism is confirmed [26]; (b) candidates for (systemic) prophylaxis of viral infection and transition to COVID-19. The over-the-counter drugs bromhexine, ambroxol, loratadine, desloratadine, azelastine, and diphenhydramine are assumed to contribute significantly to viral infection prophylaxis and frequency in less affected countries such as Germany. Unless indicated, lysosomotropism is highly probable, but not confirmed. $\left.{ }^{*}\right)$ lysosomotropism is confirmed, $\left({ }^{\#}\right)$ no lysosomotropism, $\left({ }^{* *}\right)$ nasal and ophthalmic $\mathrm{H}_{1}$-antihistamine. Levofloxacin exhibits anti-inflammatory effects on prominent inflammatory messengers in mice with LPS-induced acute lung injuries [43], comparable to NB 06 in LPS-induced inflammation [22].

\section{Fluvoxamine: Tackling Dyspnea in COVID-19}

Fluvoxamine is another approved drug with a molecular structure suggesting lysosomotropism that has been recently successfully tested for its efficacy in COVID 19. One hundred and fifty-two adult outpatients with confirmed COVID-19 and symptom onset within day seven were treated with fluvoxamine (up to $300 \mathrm{mg} /$ day) and compared with placebo. The randomized preliminary clinical trial demonstrated a statistically significant lower likelihood of clinical deterioration (low oxygen saturation $(<92 \%)$ and presence of dyspnea, or hypoxia) over 15 days (0 vs. $6(8.3 \%)$ with placebo $(n=66))$ [44]. In general, fluvoxamine is a well-tolerated, selective serotonin reuptake inhibitor (SSRI) with a broad therapeutic window (lower QT-prolonging potential [45]) used daily in doses up to $300 \mathrm{mg}$. Moreover, fluvoxamine is rated as a strong $\sigma-1$ receptor (S1R) agonist, reducing the damaging aspects of the inflammatory response during sepsis through the S1R-IRE1 pathway and 
decreasing shock in murine sepsis models [46] similar to lysosomotropic desipramine [23]. This, together with its strong lipophilicity and rapid intracellular uptake [47], supports distinct lysosomotropic characteristics of fluvoxamine.

Although the adverse events during the clinical trial have been moderate, the incidence of serious drug interactions, characteristic psychiatric adverse reactions of SSRI (e.g., trouble sleeping, insomnia (up to $35 \%$ ), mood or behavior changes, anxiety, and panic attacks), and dermatologic adverse reactions (skin rash, blisters, or hives) [48] can be reasonably expected to increase with large-scale and high-dose usage.

\section{Drug Repurposing Lessons Learned from (Hydroxy) Chloroquine in Clinical Trials}

Both chloroquine and hydroxychloroquine were demonstrated in cell culture experiments to prevent SARS-CoV-2 infection [11,49,50]; however, they have failed to demonstrate their benefits in clinical trials, leading to a dissuasion from the application [1]. Compounds and their metabolites (e.g., chloroquine and desethylchloroquine) with (very) long terminal elimination half-life ( $45 \pm 15$ days chloroquine [51-53], $41 \pm 11$ days hydroxychloroquine $[53,54]$ ), and poor and/or delayed pulmonary accumulation (steady state on day 10 [55]) of both compounds are inappropriate in terms of adverse effects (e.g., dysrhythmias, often occurring in combination with other drugs such as azithromycin (lysosomotropism presumed), prolonging the QTc interval in and beyond the therapeutic window [1,56,57]).

In particular, the high dosage of, e.g., $600 \mathrm{mg}$ hydroxychloroquine daily for 7 days in the treatment of (mild) COVID-19 [58], in combination with the long elimination halflife of both compounds, 30-60 days and varying substantially from one person to another, impedes therapy management and increases the risk of unacceptable serious adverse effects. Oxidative stress resulting from SARS infection in animal models of [59] implies a high risk of serious adverse reactions such as hemolysis and methemoglobinemia in glucose-6-phosphate dehydrogenase (G6PD)-deficient patients, if treated with (hydroxy) chloroquine [60].

The disappointing results of (hydroxy) chloroquine contrast with the encouraging clinical data of chlorpromazine [17] and fluvoxamine [44]. All of them have lysosomotropism in common; however, they differ in their drug profile. This encourages a quest for alternative lysosomotropic drugs with a more suitable drug profile (lower elimination half-life and lower dosage - required for lysosomotropic drug concentration in pulmonary tissuebetter G6PD tolerance, a broader therapeutic window, and lower (cardiac) toxicity).

\section{Quest for Further Lysosomotropic (Active) Compounds}

Lysosomotropism is a noteworthy biological characteristic of small molecules, independently present in addition to their intrinsic pharmacological effects. Various well-known approved drugs, e.g., amitriptyline, amlodipine, chlorpromazine, doxepine, and sertraline [26], share lysosomotropic characteristics. In silicio, search methods such as the SPAR model [26] or the QSAR model [5] are useful tools to identify existing highly accumulating lysosomotropic drugs. Their shortcoming, however, is that the search is focused on wellknown drugs, neglecting resulting active metabolites and the respective bioavailability as well as accumulation in pulmonary tissue. The pair consisting of the parent compound loratadine (no lysosomotropism) [26] and the metabolite desloratadine (lysosomotropism, anti-inflammatory in mice lungs) [61] is an example of the shortcoming of both models.

\section{Metabolites and Lung Accumulation}

Investigations by toxicologists on the accumulation of various psychotropic drugs in lung tissue have provided interesting results regarding lysosomotropic drugs and their major metabolites. Both parent compounds and N-desmethyl metabolites of, e.g., fluoxetine, citalopram, mirtazapine, and amitriptyline, accumulate in pulmonary tissue. Most commonly, the metabolites and the parent compounds are hardly structurally different (e.g., fluoxetine/norfluoxetine, citalopram/desmethyl citalopram) (Figure 2a). Normirtazapine, 
on the contrary, accumulates more than five times more in the lung tissue than mirtazapine. By taking advantage of lysosomal trapping and enrichment, a lysosomotropic drug concentration in pulmonary tissue and thus a preventive effect analogous to chlorpromazine can be achieved with, e.g., multiple low therapeutic dosing of mirtazapine.

\section{Targeted Drug Repurposing}

Starting from the aforementioned findings, a new strategy for rational drug targeting can be derived for candidate drugs affecting the endolysosomal pathway of viral infection and providing anti-inflammatory effects in pulmonary tissue and, thus, in vivo. The flowchart in Figure 3 may be helpful to choose suitable lysosmotropic drugs and/or precursors of lysosomotropic metabolites meeting these requirements. Candidates are lipophilic-weak at $\mathrm{pH}$ 4.5-5.5 proton able bases containing at least one aliphatic (cyclic) amine residue meeting the following criteria (according to [22,26,62]): lysosomotropism is present within the therapeutic margin, no or acceptable undesirable systemic pharmacological effects at lysosomotropic drug concentrations, favorable systemic drug profile or local application as expedient, and accumulation in pulmonary tissue after systemic application. The lack of lysosomotropism of 2-hydroxy and 10-hydroxy derivatives of imipramine [26] suggests that hydroxyl group containing metabolites are unlikely to provide benefit in this context.

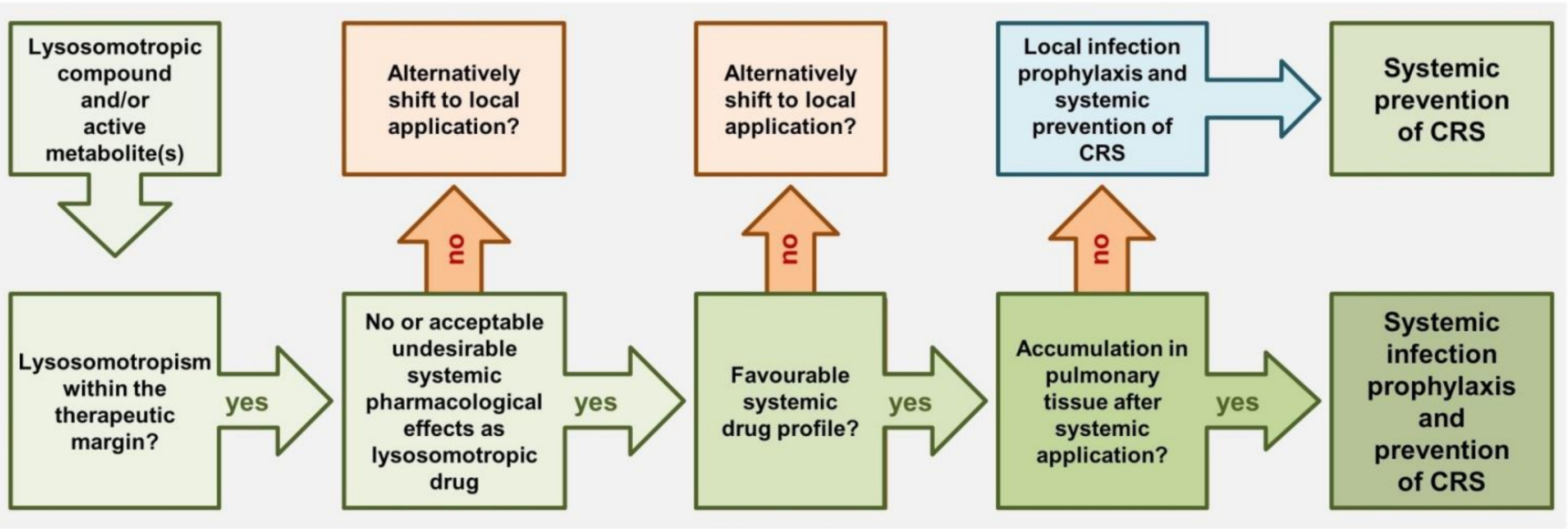

Figure 3. Flowchart for choosing suitable lysosomotropic drugs for (systemic) infection prophylaxis and prevention of transition to COVID-19 according to Table 1. Candidates (active compounds and/or one or more metabolites) should meet the following criteria: lipophilic, weak protonatable nitrogen bases where lysosomotropism is present within the therapeutic margin, no or acceptable undesirable systemic pharmacological effects as lysosomotropic drug are known, favorable systemic drug profile or local application as expedient, and accumulation in pulmonary tissue after systemic application.

\section{Candidates for (Systemic) Prophylaxis of Viral Infection and Transition to COVID-19}

The pairs in Figure 2a,b are, in general, new promising drugs (and precursors) for prophylaxis and treatment of SARS-CoV-2 infection of airway epithelial cells. Like chlorpromazine, the psychotropic drugs mirtazapine, normirtazapine, amitriptyline, nortriptyline, fluoxetine, and citalopram, and the antiemetic metoclopramide, are inappropriate for systemic prophylaxis in healthy individuals.

In contrast, the OTC drugs bromhexine/ambroxol, diphenhydramine, and loratadine, by its active metabolite desloratadine, may provide a substantial contribution to prophylaxis and systemic therapy and the approved nasal applicable azelastine to nasal prophylaxis. Their therapeutic window is broader, the drug profile is safer, and the generic adverse effects of lysosomotropic prescription drugs (e.g., QTc prolongation, Torsade de Pointes, ventricular arrhythmia, bundle branch heart block, and cardiac deaths, in particular from overdosing) are very rare (loratadine/desloratadine) [63] or absent (ambroxol) [64]. 


\section{Defined Daily Doses (DDD) of Commonly Used (Presumable) Lysosmotropic Drugs and Prodrugs}

However, since some of the drugs in Figure 2a,b are already and frequently used therapeutically, it is reasonable to assume that they may contribute significantly to viral infection prophylaxis in less affected countries such as Germany. In particular, ambroxol, loratadine, and its active metabolite desloratadine are widely used antiallergics in Germany. To gain an overview of the frequency of use of some of the listed candidates and the associated probable effects on the frequency of infection, the number of DDD prescriptions is a starting point. According to prescriptions charged to the statutory health insurance in Germany, amitriptyline (75 mg DDD/83.1 mio DDD), citalopram (20 mg/294.7), escitalopram (10 mg/110.5), fluoxetine (20 mg/62.2), mirtazapine (150 mg/185.4), sertraline (50 mg/143.0), and ciprofloxacin (1000 mg/19,3) (2016); promethazine (75 mg/31.4) (2017); and metoprolol (150 mg/834.9) (2018) were prescribed [65]. The data suggest that psychotropic drugs previously identified as lysosomotropic are widely used. Due to their piperazine residue, the antibiotics ciprofloxacin and levofloxacin are very likely to share lysosomotropic characteristics. They may be useful in bacterial pneumonia and show antiinflammatory effects in LPS-induced acute lung injuries [43], such as NB 06 in LPS-treated monocytes [22], suggesting a common mode of action.

\section{Conclusions}

Encouraging results in vitro and of chlorpromazine and fluvoxamine in vivo suggest that lysosomotropic compounds might be used as tools in fighting SARS-CoV-2 infections by potentially triggering a variety of cellular modifications that impede alveolar cell infection and viral replication (Figure 1). The modulating effects of lysosomotropism of drugs and their metabolites on gene expression of various cytokines and interleukins is likely to provide a means of preventing the development of CRS and, concomitantly, the rapid, severe, and serious deterioration in COVID-19 without massive interventions in the immune system.

Lysosomotropism is present in an enormous number of active compounds and metabolites, but such activity has been confirmed only in a few so far. The eligibility criteria, lysosomotropism, drug profile, and inevitable lysosomal accumulation in pulmonary tissue described here (Figure 3) provide a guideline for picking promising candidates from the pool of approved drugs for future investigations and clinical trials. If further confirmed, the concept may contribute more rapidly accessible options for preventing SARS-Cov-2 infections, the transition to COVID-19, and providing protection of endothelial stress response in systemic inflammation. Moreover, further infectious diseases such as influenza A (H1N1) can be addressed, where $\mathrm{pH}$ in lysosomes, IL-6, and lysosomal sphingolipid metabolism play a crucial role.

Author Contributions: M.B. conceived the work; M.B., L.K., O.S., R.C. and H.-P.D. wrote the manuscript. All authors have read and agreed to the published version of the manuscript.

Funding: Funding from the Institute of Precision Medicine; the Federal Ministry of Science, Research and Art of Baden-Württemberg, Germany (researchership for L.K.); and the Institute for Applied Research (IAF), Furtwangen University (VS-Schwenningen, Germany) is gratefully acknowledged. The article processing charge was funded by the Baden-Württemberg Ministry of Science, Research, and Culture and the Furtwangen University in the funding program Open Access Publishing.

Institutional Review Board Statement: Not applicable.

Informed Consent Statement: Not applicable.

Data Availability Statement: Not applicable.

Acknowledgments: We thank Edith Walther for her tremendous technical support in performing elaborate cell experiments and sample preparation in the initial stages of conceptual work. Tremendous support by Petra and Peter Bauer, the staff at Riesling Apotheke (Ellerstadt, Ger- 
many), Europa Apotheke (Bensheim, Germany), and Apotheke im Markt (Heidelberg, Germany) is gratefully acknowledged.

Conflicts of Interest: The authors declare no conflict of interest.

$\begin{array}{ll}\text { Abbreviations } \\ \text { ACE2 } & \text { Angiotensin-converting enzyme 2 } \\ \text { aCERase } & \text { lysosomal acidic ceramidase } \\ \text { ARDS } & \text { acute respiratory distress syndrome } \\ \text { COVID-19 } & \text { Coronavirus disease 2019 } \\ \text { CRS } & \text { cytokine release syndrome } \\ \text { DDD } & \text { defined daily dose } \\ \text { ELOVL } & \text { elongation of very long chain fatty acids protein } \\ \text { G6PD } & \text { glucose-6-phosphate dehydrogenase } \\ \text { HLA-DR } & \text { human leukocyte antigen-D related } \\ \text { IL-1R } & \text { IL-1 receptor } \\ \text { IL-6R } & \text { IL-6 receptor } \\ \text { IRE1 } & \text { inositol-requiring enzyme 1 } \alpha \\ \text { LPS } & \text { lipopolysaccharide } \\ \text { RdRp } & \text { RNA-dependent RNA polymerase } \\ \text { SARS } & \text { severe acute respiratory syndrome } \\ \text { SSRI } & \text { selective serotonin reuptake inhibitor } \\ \text { TLR4 } & \text { toll-like receptor 4 } \\ \text { TMPRSS2 } & \text { transmembrane serine protease 2, transmembrane protease serine 2 } \\ \text { V-ATPase } & \text { vacuolar H }{ }^{+} \text {-ATPase }\end{array}$

\section{References}

1. COVID-19 Treatment Guidelines Panel Coronavirus Disease 2019 (COVID-19) Treatment Guidelines. Available online: https: //www.covid19treatmentguidelines.nih.gov / (accessed on 17 December 2020).

2. Blaess, M.; Kaiser, L.; Sauer, M.; Csuk, R.; Deigner, H.-P. COVID-19/SARS-CoV-2 Infection: Lysosomes and Lysosomotropism Implicate New Treatment Strategies and Personal Risks. Int. J. Mol. Sci. 2020, 21, 4953. [CrossRef]

3. Glebov, O.O. Understanding SARS-CoV-2 Endocytosis for COVID-19 Drug Repurposing. FEBS J. 2020. [CrossRef]

4. Schloer, S.; Brunotte, L.; Goretzko, J.; Mecate-Zambrano, A.; Korthals, N.; Gerke, V.; Ludwig, S.; Rescher, U. Targeting the Endolysosomal Host-SARS-CoV-2 Interface by Clinically Licensed Functional Inhibitors of Acid Sphingomyelinase (FIASMA) Including the Antidepressant Fluoxetine. Emerg. Microbes Infect. 2020, 9, 2245-2255. [CrossRef] [PubMed]

5. Norinder, U.; Tuck, A.; Norgren, K.; Munic Kos, V. Existing Highly Accumulating Lysosomotropic Drugs with Potential for Repurposing to Target COVID-19. Biomed. Pharmacother. 2020, 130, 110582. [CrossRef]

6. Ballout, R.A.; Sviridov, D.; Bukrinsky, M.I.; Remaley, A.T. The Lysosome: A Potential Juncture between SARS-CoV-2 Infectivity and Niemann-Pick Disease Type C, with Therapeutic Implications. FASEB J. 2020, 34, 7253-7264. [CrossRef] [PubMed]

7. Al-Bari, M.A.A. Targeting Endosomal Acidification by Chloroquine Analogs as a Promising Strategy for the Treatment of Emerging Viral Diseases. Pharm. Res. Perspect. 2017, 5, e00293. [CrossRef] [PubMed]

8. Hoffmann, M.; Kleine-Weber, H.; Schroeder, S.; Krüger, N.; Herrler, T.; Erichsen, S.; Schiergens, T.S.; Herrler, G.; Wu, N.-H.; Nitsche, A.; et al. SARS-CoV-2 Cell Entry Depends on ACE2 and TMPRSS2 and Is Blocked by a Clinically Proven Protease Inhibitor. Cell 2020, 181, 271-280.e8. [CrossRef]

9. Mingo, R.M.; Simmons, J.A.; Shoemaker, C.J.; Nelson, E.A.; Schornberg, K.L.; D’Souza, R.S.; Casanova, J.E.; White, J.M. Ebola Virus and Severe Acute Respiratory Syndrome Coronavirus Display Late Cell Entry Kinetics: Evidence That Transport to NPC1 ${ }^{+}$ Endolysosomes Is a Rate-Defining Step. J. Virol. 2015, 89, 2931-2943. [CrossRef]

10. Zhou, N.; Pan, T.; Zhang, J.; Li, Q.; Zhang, X.; Bai, C.; Huang, F.; Peng, T.; Zhang, J.; Liu, C.; et al. Glycopeptide Antibiotics Potently Inhibit Cathepsin L in the Late Endosome/Lysosome and Block the Entry of Ebola Virus, Middle East Respiratory Syndrome Coronavirus (MERS-CoV), and Severe Acute Respiratory Syndrome Coronavirus (SARS-CoV). J. Biol. Chem. 2016, 291, 9218-9232. [CrossRef]

11. Liu, J.; Cao, R.; Xu, M.; Wang, X.; Zhang, H.; Hu, H.; Li, Y.; Hu, Z.; Zhong, W.; Wang, M. Hydroxychloroquine, a Less Toxic Derivative of Chloroquine, Is Effective in Inhibiting SARS-CoV-2 Infection in Vitro. Cell Discov. 2020, 6, 16. [CrossRef]

12. Weston, S.; Coleman, C.M.; Haupt, R.; Logue, J.; Matthews, K.; Li, Y.; Reyes, H.M.; Weiss, S.R.; Frieman, M.B. Broad AntiCoronaviral Activity of FDA Approved Drugs against SARS-CoV-2 in Vitro and SARS-CoV in Vivo. J. Virol. 2020. [CrossRef]

13. Gorshkov, K.; Chen, C.Z.; Bostwick, R.; Rasmussen, L.; Tran, B.N.; Cheng, Y.-S.; Xu, M.; Pradhan, M.; Henderson, M.; Zhu, W.; et al. The SARS-CoV-2 Cytopathic Effect Is Blocked by Lysosome Alkalizing Small Molecules. ACS Infect. Dis. 2020. [CrossRef] [PubMed] 
14. Ou, X.; Liu, Y.; Lei, X.; Li, P.; Mi, D.; Ren, L.; Guo, L.; Guo, R.; Chen, T.; Hu, J.; et al. Characterization of Spike Glycoprotein of SARS-CoV-2 on Virus Entry and Its Immune Cross-Reactivity with SARS-CoV. Nat. Commun. 2020, 11, 1620. [CrossRef]

15. Yamamoto, M.; Kiso, M.; Sakai-Tagawa, Y.; Iwatsuki-Horimoto, K.; Imai, M.; Takeda, M.; Kinoshita, N.; Ohmagari, N.; Gohda, J.; Semba, K.; et al. The Anticoagulant Nafamostat Potently Inhibits SARS-CoV-2 S Protein-Mediated Fusion in a Cell Fusion Assay System and Viral Infection In Vitro in a Cell-Type-Dependent Manner. Viruses 2020, 12, 629. [CrossRef] [PubMed]

16. de Wit, E.; Feldmann, F.; Cronin, J.; Jordan, R.; Okumura, A.; Thomas, T.; Scott, D.; Cihlar, T.; Feldmann, H. Prophylactic and Therapeutic Remdesivir (GS-5734) Treatment in the Rhesus Macaque Model of MERS-CoV Infection. Proc. Natl. Acad. Sci. USA 2020, 117, 6771-6776. [CrossRef]

17. Plaze, M.; Attali, D.; Petit, A.-C.; Blatzer, M.; Simon-Loriere, E.; Vinckier, F.; Cachia, A.; Chrétien, F.; Gaillard, R. Repositionnement de la chlorpromazine dans le traitement du COVID-19: étude reCoVery. L'Encéphale 2020, 46, S35-S39. [CrossRef]

18. Chen, T.; Wu, D.; Chen, H.; Yan, W.; Yang, D.; Chen, G.; Ma, K.; Xu, D.; Yu, H.; Wang, H.; et al. Clinical Characteristics of 113 Deceased Patients with Coronavirus Disease 2019: Retrospective Study. BMJ 2020, m1091. [CrossRef]

19. Giamarellos-Bourboulis, E.J.; Netea, M.G.; Rovina, N.; Akinosoglou, K.; Antoniadou, A.; Antonakos, N.; Damoraki, G.; Gkavogianni, T.; Adami, M.-E.; Katsaounou, P.; et al. Complex Immune Dysregulation in COVID-19 Patients with Severe Respiratory Failure. Cell Host Microbe 2020, 27, 992-1000.e3. [CrossRef] [PubMed]

20. Lee, D.W.; Gardner, R.; Porter, D.L.; Louis, C.U.; Ahmed, N.; Jensen, M.; Grupp, S.A.; Mackall, C.L. Current Concepts in the Diagnosis and Management of Cytokine Release Syndrome. Blood 2014, 124, 188-195. [CrossRef] [PubMed]

21. Moore, J.B.; June, C.H. Cytokine Release Syndrome in Severe COVID-19. Science 2020, 368, 473-474. [CrossRef]

22. Blaess, M.; Bibak, N.; Claus, R.A.; Kohl, M.; Bonaterra, G.A.; Kinscherf, R.; Laufer, S.; Deigner, H.-P. NB 06: From a Simple Lysosomotropic ASMase Inhibitor to Tools for Elucidating the Role of Lysosomes in Signaling Apoptosis and LPS-Induced Inflammation. Eur. J. Med. Chem. 2018, 153, 73-104. [CrossRef]

23. Chung, H.-Y.; Kollmey, A.; Schrepper, A.; Kohl, M.; Bläss, M.; Stehr, S.; Lupp, A.; Gräler, M.; Claus, R. Adjustment of Dysregulated Ceramide Metabolism in a Murine Model of Sepsis-Induced Cardiac Dysfunction. Int. J. Mol. Sci. 2017, 18, 839. [CrossRef]

24. Manchanda, H.; Seidel, N.; Blaess, M.F.; Claus, R.A.; Linde, J.; Slevogt, H.; Sauerbrei, A.; Guthke, R.; Schmidtke, M. Differential Biphasic Transcriptional Host Response Associated with Coevolution of Hemagglutinin Quasispecies of Influenza A Virus. Front. Microbiol. 2016, 7. [CrossRef] [PubMed]

25. Vincent, M.J.; Bergeron, E.; Benjannet, S.; Erickson, B.R.; Rollin, P.E.; Ksiazek, T.G.; Seidah, N.G.; Nichol, S.T. Chloroquine Is a Potent Inhibitor of SARS Coronavirus Infection and Spread. Virol. J. 2005, 2, 69. [CrossRef]

26. Kornhuber, J.; Tripal, P.; Reichel, M.; Terfloth, L.; Bleich, S.; Wiltfang, J.; Gulbins, E. Identification of New Functional Inhibitors of Acid Sphingomyelinase Using a Structure-Property-Activity Relation Model. J. Med. Chem. 2008, 51, 219-237. [CrossRef] [PubMed]

27. Dyall, J.; Coleman, C.M.; Hart, B.J.; Venkataraman, T.; Holbrook, M.R.; Kindrachuk, J.; Johnson, R.F.; Olinger, G.G.; Jahrling, P.B.; Laidlaw, M.; et al. Repurposing of Clinically Developed Drugs for Treatment of Middle East Respiratory Syndrome Coronavirus Infection. Antimicrob. Agents Chemother. 2014, 58, 4885-4893. [CrossRef] [PubMed]

28. Carpinteiro, A.; Edwards, M.J.; Hoffmann, M.; Kochs, G.; Gripp, B.; Weigang, S.; Adams, C.; Carpinteiro, E.; Gulbins, A.; Keitsch, S.; et al. Pharmacological Inhibition of Acid Sphingomyelinase Prevents Uptake of SARS-CoV-2 by Epithelial Cells. Cell Rep. Med. 2020, 1, 100142. [CrossRef] [PubMed]

29. Hoffmann, M.; Schroeder, S.; Kleine-Weber, H.; Müller, M.A.; Drosten, C.; Pöhlmann, S. Nafamostat Mesylate Blocks Activation of SARS-CoV-2: New Treatment Option for COVID-19. Antimicrob. Agents Chemother. 2020, 64, e00754-20. [CrossRef] [PubMed]

30. Tang, N.; Ong, W.-Y.; Zhang, E.-M.; Chen, P.; Yeo, J.-F. Differential Effects of Ceramide Species on Exocytosis in Rat PC12 Cells. Exp. Brain Res. 2007, 183, 241-247. [CrossRef]

31. Ghosh, S.; Dellibovi-Ragheb, T.A.; Kerviel, A.; Pak, E.; Qiu, Q.; Fisher, M.; Takvorian, P.M.; Bleck, C.; Hsu, V.W.; Fehr, A.R.; et al. $\beta$ Coronaviruses Use Lysosomes for Egress Instead of the Biosynthetic Secretory Pathway. Cell 2020, 183, 1520-1535.e14. [CrossRef]

32. He, X.; Okino, N.; Dhami, R.; Dagan, A.; Gatt, S.; Schulze, H.; Sandhoff, K.; Schuchman, E.H. Purification and Characterization of Recombinant, Human Acid Ceramidase. Catalytic Reactions and Interactions with Acid Sphingomyelinase. J. Biol. Chem. 2003, 278, 32978-32986. [CrossRef]

33. Okino, N.; He, X.; Gatt, S.; Sandhoff, K.; Ito, M.; Schuchman, E.H. The Reverse Activity of Human Acid Ceramidase. J. Biol. Chem. 2003, 278, 29948-29953. [CrossRef]

34. Naganuma, T.; Kihara, A. Two Modes of Regulation of the Fatty Acid Elongase ELOVL6 by the 3-Ketoacyl-CoA Reductase KAR in the Fatty Acid Elongation Cycle. Plos One 2014, 9, e101823. [CrossRef]

35. Pillay, C.S.; Elliott, E.; Dennison, C. Endolysosomal Proteolysis and Its Regulation. Biochem. J. 2002, 363, 417-429. [CrossRef]

36. Gille, L.; Nohl, H. The Existence of a Lysosomal Redox Chain and the Role of Ubiquinone. Arch. Biochem. Biophys. 2000, 375, 347-354. [CrossRef] [PubMed]

37. Blaess, M.; Deigner, H.-P. Derailed Ceramide Metabolism in Atopic Dermatitis (AD): A Causal Starting Point for a Personalized (Basic) Therapy. Int. J. Mol. Sci. 2019, 20, 3967. [CrossRef] [PubMed]

38. Bickel, M.H.; Graber, B.E.; Moor, M. Distribution of Chlorpromazine and Imipramine in Adipose and Other Tissues of Rats. Life Sci. 1983, 33, 2025-2031. [CrossRef]

39. Drugs.com Chlorpromazine. Available online: https:/ / www.drugs.com/mtm/chlorpromazine.html (accessed on 26 January 2021). 
40. Wenzel, S.; Aderjan, R.; Mattern, R.; Pedal, I.; Skopp, G. Tissue Distribution of Mirtazapine and Desmethylmirtazapine in a Case of Mirtazapine Poisoning. Forensic. Sci. Int. 2006, 156, 229-236. [CrossRef]

41. Johnson, R.D.; Lewis, R.J.; Angier, M.K. The Distribution of Fluoxetine in Human Fluids and Tissues. J. Anal. Toxicol. 2007, 31, 409-414. [CrossRef]

42. Brockbals, L.; Staeheli, S.N.; Gascho, D.; Ebert, L.C.; Kraemer, T.; Steuer, A.E. Time- and Site-Dependent Postmortem Redistribution of Antidepressants and Neuroleptics in Blood and Alternative Matrices. J. Anal. Toxicol. 2020, bkaa092. [CrossRef]

43. Huang, H.-C.; Shieh, C.-C.; Yu, W.-L.; Cheng, K.-C.; Chen, C.-C.; Chang, S.-T.; Chuang, Y.-C. Comparing the Protective Effects of Ciprofloxacin, Moxifloxacin and Levofloxacin in Mice with Lipopolysaccharide-Induced Acute Lung Injuries: Comparing Quinolones in Lung Injuries. Respirology 2008, 13, 47-52. [CrossRef] [PubMed]

44. Lenze, E.J.; Mattar, C.; Zorumski, C.F.; Stevens, A.; Schweiger, J.; Nicol, G.E.; Miller, J.P.; Yang, L.; Yingling, M.; Avidan, M.S.; et al. Fluvoxamine vs Placebo and Clinical Deterioration in Outpatients With Symptomatic COVID-19: A Randomized Clinical Trial. JAMA 2020, 324, 2292. [CrossRef] [PubMed]

45. Assimon, M.M.; Brookhart, M.A.; Flythe, J.E. Comparative Cardiac Safety of Selective Serotonin Reuptake Inhibitors among Individuals Receiving Maintenance Hemodialysis. J. Am. Soc. Nephrol. 2019, 30, 611-623. [CrossRef]

46. Rosen, D.A.; Seki, S.M.; Fernández-Castañeda, A.; Beiter, R.M.; Eccles, J.D.; Woodfolk, J.A.; Gaultier, A. Modulation of the Sigma-1 Receptor-IRE1 Pathway Is Beneficial in Preclinical Models of Inflammation and Sepsis. Sci. Transl. Med. 2019, 11, eaau5266. [CrossRef] [PubMed]

47. Hallifax, D.; Houston, J.B. Saturable Uptake of Lipophilic Amine Drugs into Isolated Hepatocytes: Mechanisms and Consequences for Quantitative Clearance Prediction. Drug Metab. Dispos. 2007, 35, 1325-1332. [CrossRef]

48. Drugs.com Fluvoxamine. Available online: https:/ / www.drugs.com/ppa/fluvoxamine.html (accessed on 26 January 2021).

49. Wang, M.; Cao, R.; Zhang, L.; Yang, X.; Liu, J.; Xu, M.; Shi, Z.; Hu, Z.; Zhong, W.; Xiao, G. Remdesivir and Chloroquine Effectively Inhibit the Recently Emerged Novel Coronavirus (2019-NCoV) in Vitro. Cell Res. 2020, 30, 269-271. [CrossRef] [PubMed]

50. Zhou, D.; Dai, S.-M.; Tong, Q. COVID-19: A Recommendation to Examine the Effect of Hydroxychloroquine in Preventing Infection and Progression. J. Antimicrob. Chemother. 2020, 75, 1667-1670. [CrossRef]

51. Krishna, S.; White, N.J. Pharmacokinetics of Quinine, Chloroquine and Amodiaquine: Clinical Implications. Clin. Pharmacokinet. 1996, 30, 263-299. [CrossRef] [PubMed]

52. Ducharme, J.; Farinotti, R. Clinical Pharmacokinetics and Metabolism of Chloroquine: Focus on Recent Advancements. Clin. Pharmacokinet. 1996, 31, 257-274. [CrossRef]

53. Rainsford, K.D.; Parke, A.L.; Clifford-Rashotte, M.; Kean, W.F. Therapy and Pharmacological Properties of Hydroxychloroquine and Chloroquine in Treatment of Systemic Lupus Erythematosus, Rheumatoid Arthritis and Related Diseases. Inflammopharmacology 2015, 23, 231-269. [CrossRef] [PubMed]

54. Schrezenmeier, E.; Dörner, T. Mechanisms of Action of Hydroxychloroquine and Chloroquine: Implications for Rheumatology. Nat. Rev. Rheumatol. 2020, 16, 155-166. [CrossRef] [PubMed]

55. Yao, X.; Ye, F.; Zhang, M.; Cui, C.; Huang, B.; Niu, P.; Liu, X.; Zhao, L.; Dong, E.; Song, C.; et al. In Vitro Antiviral Activity and Projection of Optimized Dosing Design of Hydroxychloroquine for the Treatment of Severe Acute Respiratory Syndrome Coronavirus 2 (SARS-CoV-2). Clin. Infect. Dis. 2020. [CrossRef] [PubMed]

56. CDC Malaria Treatment Guidelines. Available online: https://www.cdc.gov/malaria/resources/pdf/Malaria_Treatment_Guid elines.pdf (accessed on 26 January 2021).

57. Borba, M.G.S.; Val, F.F.A.; Sampaio, V.S.; Alexandre, M.A.A.; Melo, G.C.; Brito, M.; Mourão, M.P.G.; Brito-Sousa, J.D.; Baía-daSilva, D.; Guerra, M.V.F.; et al. Effect of High vs Low Doses of Chloroquine Diphosphate as Adjunctive Therapy for Patients Hospitalized With Severe Acute Respiratory Syndrome Coronavirus 2 (SARS-CoV-2) Infection: A Randomized Clinical Trial. JAMA Netw. Open 2020, 3, e208857. [CrossRef] [PubMed]

58. NCT04340544 Hydroxychloroquine for the Treatment of Mild COVID-19 Disease (COMIHY). Available online: https:/ clinicaltr ials.gov/ct2/show/NCT04340544 (accessed on 5 June 2020).

59. Delgado-Roche, L.; Mesta, F. Oxidative Stress as Key Player in Severe Acute Respiratory Syndrome Coronavirus (SARS-CoV) Infection. Arch. Med. Res. 2020, 51, 384-387. [CrossRef]

60. Palmer, K.; Dick, J.; French, W.; Floro, L.; Ford, M. Methemoglobinemia in Patient with G6PD Deficiency and SARS-CoV-2 Infection. Emerg. Infect. Dis. 2020, 26. [CrossRef]

61. Bryce, P.J.; Geha, R.; Oettgen, H.C. Desloratadine Inhibits Allergen-Induced Airway Inflammation and Bronchial Hyperresponsiveness and Alters T-Cell Responses in Murine Models of Asthma. J. Allergy Clin. Immunol. 2003, 112, 149-158. [CrossRef]

62. De Duve, C.; De Barsy, T.; Poole, B.; Trouet, A.; Tulkens, P.; Van Hoof, F. Lysosomotropic Agents. Biochem. Pharmacol. 1974, 23, 2495-2531. [CrossRef]

63. Drugs.com Loratadine. Available online: https://www.drugs.com/loratadine.html (accessed on 26 January 2021).

64. Drugs.com Ambroxol. Available online: https://www.drugs.com/ambroxol.html (accessed on 26 January 2021).

65. IGES Institut Development of Prescriptions Charged to the Statutory Health Insurance in Germany. Available online: https: //www.arzneimittel-atlas.de (accessed on 20 October 2020). 